\title{
PENYEBAB CHANGE ORDER PADA PROYEK PERKERASAN JALAN
}

\author{
Philander Edward ${ }^{1}$ dan Mega Waty ${ }^{2}$ \\ ${ }^{1}$ Program Studi Sarjana Teknik Sipil, Universitas Tarumanagara, Jl. Letjen S. Parman No.1 Jakarta \\ Philanderedward75@gmail.com \\ ${ }^{2}$ Program Studi Sarjana Teknik Sipil, Universitas Tarumanagara, J1. Letjen S. Parman No.1 Jakarta \\ mega@ft.untar.ac.id
}

\begin{abstract}
In the implementation of construction projects, there are several important elements that must be done well. so that the essential elements can be carried out well, then agreement regarding certain matters is agreed upon by the parties concerned which is called contract. Almost construction projects in Indonesia have experienced contract changes or can be called Change Order. Change Order is an event due to changes in a job that results in changes in time and cost during implementation. To solve the problem of Change order this contract can be finalized and anticipated by knowing the factors causing it in advance. The causal factors are arranged into a questionnaire to find out the main causes of Change Order. The questionnaire was distributed to contractors on the road project. Validity and reliability testing is done on the data obtained from the results of the questionnaire to obtain the consistency and stability of each question in the questionnaire. Valid and reliable question items are further analyzed using the RII method. To find out the main cause, the data is calculated using the RII. The results of the RII ranking technique show that the order acceleration schedule is the main cause of Change Order.
\end{abstract}

Keywords: Causes of Change Order, Change Order, RII, Contract, Jabodetabek.

\begin{abstract}
ABSTRAK
Dalam pelaksanaan proyek konstruksi, terdapat beberapa unsur penting yang harus dilakukan dengan baik. agar unsur unsur penting dapat terlaksana dengan baik maka dibuatlah perjanjian/ kesepakatan antara dua orang atau lebih mengenai hal tertentu yang disetujui oleh pihak pihak yang bersangkutan yang terikat yang disebut kontrak. Hampir seluruh proyek konstruksi di Indonesia mengalami terjadinya perubahan kontrak atau dapat disebut Change Order. Change Order merupakan suatu kejadian akibat perubahan suatu pekerjaan yang mengakibatkan perubahan waktu dan biaya saat pelaksanaan. Untuk mengatasi masalah Change order/ addendum kontrak ini dapat diminalisir dan diantisipasi dengan mengetahui faktor penyebabnya terlebih dahulu. Faktor-faktor penyebab tersebut disusun menjadi sebuah kuesioner untuk mengetahui penyebab utama dari Change Order. Penyebaran kuesioner tersebut dilakukan terhadap kontraktor pada proyek jalan. Pengujian uji validitas dan uji reliabilitas dilakukan terhadap data yang diperoleh dari hasil kuesioner untuk memperoleh keakuratan konsistensi dan kestabilan setiap pertanyaan dalam kuesioner. Butir pertanyaan yang valid dan reliabel dianalisis lebih lanjut menggunakan metode RII. Untuk mengetahui penyebab utama, data dihitung menggunakan teknik ranking RII (Relative Importance Index). Hasil dari teknik ranking RII menunjukan bahwa perintah percepatan jadwal merupakan faktor penyebab utama terjadinya Change Order.
\end{abstract}

Kata kunci: Penyebab Change Order, Change Order, RII, Kontrak, Jabodetabek

\section{PENDAHULUAN}

Dalam pelaksanaan proyek konstruksi, terdapat beberapa unsur penting yang harus dilakukan dengan baik diantaranya adalah biaya, mutu, dan waktu. Agar unsur unsur penting dapat terlaksana dengan baik maka dibuatlah perjanjian/ kesepakatan antara dua orang atau lebih mengenai hal tertentu yang disetujui oleh pihak pihak yang bersangkutan yang terikat yang disebut kontrak. Namun hampir seluruh proyek konstruksi di Indonesia mengalami terjadinya perubahan kontrak atau dapat disebut Change Order/ Addendum kontrak. Dengan adanya addendum kontrak, sangat mempengaruhi terjadinya perubahan harga, biaya serta waktu dalam suatu konstruksi. (Barrie dan Paulson, 1992 dalam Mega, 2013) Change Order/ Addendum kontrak merupakan dokumen formal yang ditandatangani oleh pemilik dan kontraktor untuk mengganti kerugian kontraktor karena adanya perubahan, penambahan pekerjaan, penundaan, atau kegiatan lain dengan persetujuan pemilik dan kontraktor seperti yang 
tertera pada syarat-syarat dokumen kontrak. Change Order/ Addendum kontrak dapat terjadi pada tahap awal, tengah, atau tahap akhir pada proyek konstruksi. Change order/ addendum kontrak dapat dilakukan baik oleh pihak owner maupun pihak pemilik, dan dapat terjadi pada proyek pemerintah dan juga swasta. Change Order/ Addendum kontrak secara tidak langsung mencerminkan seolah - olah kurang baiknya perencanaan dan kurang tepatnya usaha antisipasi terhadap berbagai faktor dan permasalahan, baik secara teknis maupun nonteknis.

Meskipun segala sesuatunya telah diusahakan secara optimal, catatan para pengelola proyek menunjukan bahwa change order tidak dapat dihindari. Metode konvensionalnya adalah dengan memasukan persentase dari biaya proyek dalam anggaran kontrak untuk kejadian tersebut.

Untuk mengatasi masalah Change order/ addendum kontrak ini dapat diminalisir dan diantisipasi dengan mengetahui faktor penyebabnya terlebih dahulu. Faktor penyebab Change order/ addendum kontrak sangat beragam, tidak sama antara satu proyek dengan yang lainnya. Oleh karena itu dalam penelitian ini penulis memfokuskan pada penyebab terjadinya Change order/ addendum kontrak.

Tujuan dari penelitian ini adalah untuk mengetahui penyebab utama terjadinya Change Order

\section{Change Order}

Penyebab change order bermacam - macam. Ada yang merupakan kesalahan dalam bidang administrasi ada pula dalam bidang konstruksi. banyak tulisan yang menyatakan kesalahan desain adalah penyebab yang paling dominan pada change order. Ada yang disebabkan oleh pemilik, kontraktor, ataupun subkontraktor.

\section{Tipe Perubahan}

Terdapat dua tipe perubahan menurut (Gilbreath, 1992)

1. Perubahan informal

Perubahan informal adalah tindakan informal dalam mengesahkan suatu modifikasi di lapangan yang terjadi karena kesalahan bertindak. Pemilik mengarahkan kontraktor untuk melakukan pekerjaan yang berbeda dari yang ditentukan dalam kontrak atau merupakan tambahan pekerjaan untuk pekerjaan yang ditentukan dalam kontrak.

2. Perubahan formal

Perubahan formal diajukan dalam bentuk tertulis, yang diusulkan oleh pemilik yang ditujukan kepada kontraktor untuk mengubah lingkup kerja, waktu pelaksanaan, biaya-biaya atau hal-hal lain yang berbeda yang telah dispesifikasikan dalam kontrak.

\section{Tujuan Change Order}

Menurut (Fisk, 1997) tujuan change order yaitu :

1. Untuk mengubah rencana kontrak dengan metode khusus dalam pembayaran

2. Untuk mengubah spesifikasi kontrak, termasuk perubahan pembayaran dan perubahan waktu kontrak

3. Untuk persetujuan pekerjaan tambahan baru

4. Untuk tujuan administratif

5. Untuk mengikuti penyesuaian terhadap harga unit kontrak bila terjadi overruns dan underruns yang disesuaikan dengan aplikasi

6. Untuk mengajukan pengurangan biaya insentif proposal

7. Untuk mempengaruhi pembayaran yang dilakukan setelah tuntutan diselesaikan.

\section{Pengelompokan penyebab Change Order}

Dari data-data tersebut dapat disarikan lima puluh enam penyebab change order terdiri dari

1. Kebutuhan konstruksi

a. perencanaan dan desain

- kesalahan dalam perencanaan

- kesalahan dan kelalaian dalam penentuan estimasi

- kontrak yang kurang lengkap

- ketidakcocokan antara gambar dan keadaan lapangan

- spesifikasi yang tidak lengkap

- perubahan perencanaan

- penambahan ruang lingkup

- pengurangan ruang lingkup 
- penghentian pekerjaan sementara

- jadwal yang terlalu padat

- keterlambatan persetujuan desain/ perlengkapan dari pemilik

- perintah perbaikan jadwal

- perintah percepatan jadwal

- material yang tidak sesuai di lapangan

- perubahan metode konstruksi

b. kondisi bawah tanah

- penyelidikan/ tes tanah lapangan yang tidak lengkap

- peningkatan dan penyelidikan bawah tanah

- kondisi bawah tanah yang berbeda

- rembesan bawah tanah akibat penggalian

c. pertimbangan keselamatan

- pertimbangan keselamatan kerja

- pertimbangan keamanan lapangan

- tambahan fasilitas keamanan

d. kejadian alam

- tanah longsor

- banjir

- penurunan tanah

- cuaca yang tidak umum

2. Kebutuhan administrasi

a. Perubahan peraturan kerja

- Perubahan dari peraturan perencanaan kota

- Perubahan berdasarkan perlindungan lingkungan

b. Perubahan dari pihak berwenang

- Perbedaan pandangan antara pejabat pemerintah

- Perubahan penempatan awal sarana dan prasarana

- Perubahan pasar

- Dominasi wewenang atasan

c. Commissioning

- Kebutuhan tambahan untuk fungsional dan perawatan

- Kebutuhan untuk penggunaan proyek yang berhubungan

- Kebutuhan tambahan untuk pertimbangan keselamatan mendatang

d. Permohonan lingkungan sekitar

- Penambahan fasilitas untuk penduduk

- Mengulangi/menghentikan bagian konstruksi sehubungan masalah lingkungan

- Permintaan pejabat tinggi

e. Perubahan lain

- Koordinasi yang terlambat disampaikan

- Keperluan dari agensi

- Konflik kontrak dan perselisihan

3. Pihak lain yang terlibat

a. Pemilik

- Kurang control

- Ketidakmampuan pemilik

- Keterlambatan pemilik

- Hal-hal yang belum ditentukan pemilik

- Penundaan pekerjaan karena permintaan pemilik

b. Kontraktor

- Kekurangan tim kerja

- Kurang memadai alat

- Kegagalan kemampuan kontraktor

- Perselisihan tenaga kerja

- Keterlambatan kontraktor

- Rendahnya keahlian pekerja 
- Penundaan pekerjaan karena keterlambatan kontraktor

c. Pihak lain

- Ketidakmampuan pihak ketiga

- Campur tangan pihak ketiga

\section{METODE PENELITIAN}

Pada tahap pengumpulan data, Proses pengumpulan data yang dilakukan adalah dengan memperhatikan beberapa data proyek jalan di daerah Jabodetabek. Data yang dikumpulkan adalah data mengenai addendum kontrak / change order. Proses pengumpulan data juga dilakukan melalui penyebaran kuisioner terhadap kontraktor, konsultan, dan pemilik dari proyek yang bersangkutan, serta melakukan wawancara terhadap pihak-pihak terkait pada beberapa proyek data yang dijadikan sampel.

Untuk pengukuran nilai kuesioner digunakan teknik pengukuran likert. Keterangan untuk skala pengukuran faktor penyebab change order pada proyek konstruksi:

1. Tidak pernah

2. Sangat rendah

3. Sedang

4. Tinggi

5. Sangat tinggi

Proses pengumpulan data dilakukan dengan memperhatikan perubahan pekerjaan dan harga yang terjadi pada proyek tersebut, serta mengajukan kuesioner terkait dengan penyebab dalam perubahan pekerjaan tersebut.

Pada proses pengolahan data, data - data yang telah dikumpulkan kemudian diolah dan dicatat dalam bentuk tabel dalam excel. Untuk mengukur keakuratan data, maka dilakukan pengujian realibilitas dan validitas terhadap data kuesioner tersebut. Serta metode Relative Importance Index (RII) sebagai teknik Ranking untuk setiap pernyataan dan membandingkan tanggapan yang diterima dari pihak responden.

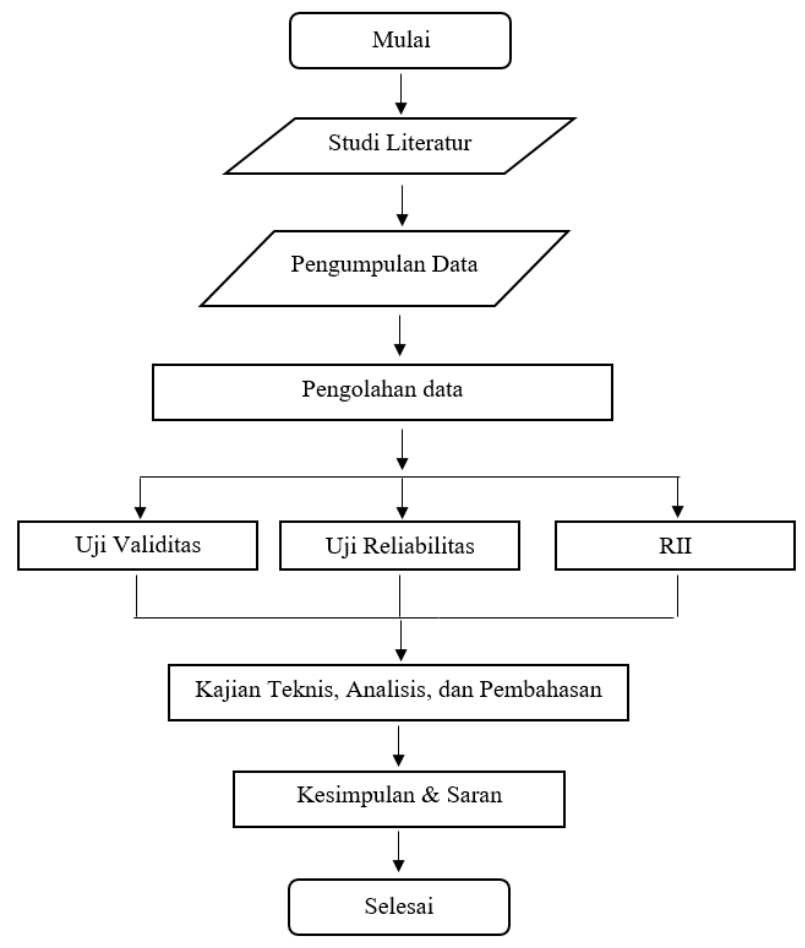

Gambar 1. Diagram Alir Penelitian 


\section{HASIL DAN PEMBAHASAN}

Berdasarkan hasil analisa perhitungan RII, maka didapat :

Tabel 1. Hasil perhitungan Relative Importance Index secara Keseluruhan

\begin{tabular}{|c|c|c|c|}
\hline NO. & FAKTOR PENYEBAB CHANGE ORDER & RII & PERINGKAT \\
\hline$\bullet$ & KEBUTUHAN KONSTRUKSI & & \\
\hline A. & PERENCANAAN DAN DESIGN & & \\
\hline 1 & Kesalahan dalam perencanaan konstruksi & 0.5 & 33 \\
\hline 2 & Kesalahan dan kelalaian dalam penentuan volume & 0.6 & 7 \\
\hline 3 & Kontrak yang kurang lengkap & 0.5 & 30 \\
\hline 4 & Ketidakcocokan antara gambar design dan keadaan lapangan & 0.6 & 1 \\
\hline 5 & Spesifikasi atau kriteria desain engineering yang kurang lengkap & 0.5 & 15 \\
\hline 6 & Perubahan gambar perencanaan & 0.6 & 1 \\
\hline 7 & Penambahan ruang lingkup kerja & 0.6 & 3 \\
\hline 8 & Pengurangan ruang lingkup kerja & 0.6 & 7 \\
\hline 9 & Penghentian pekerjaan sementara & & \\
\hline 10 & Kontrak yang bertentangan & 0.4 & 50 \\
\hline 11 & Jadwal yang terlalu padat & 0.6 & 11 \\
\hline 12 & Keterlambatan persetujuan desain/ perlengkapan dari pemilik & 0.5 & 19 \\
\hline 13 & Perintah perbaikan jadwal & 0.6 & 7 \\
\hline 14 & Perintah percepatan jadwal & - & - \\
\hline 15 & Material yang tidak sesuai di lapangan & 0.5 & 39 \\
\hline 16 & Perubahan metode konstruksi & 0.5 & 24 \\
\hline B. & KONDISI BAWAH TANAH & & \\
\hline 17 & Penyelidikan/ tes tanah lapangan yang tidak lengkap & 0.5 & 27 \\
\hline 18 & Peningkatan dan penyelidikan bawah tanah & 0.6 & 12 \\
\hline 19 & Kondisi bawah tanah yang berbeda terhadap hasil penyelidikan & 0.6 & 13 \\
\hline 20 & Rembesan bawah tanah akibat penggalian & 0.5 & 25 \\
\hline C. & PERTIMBANGAN KESELAMATAN & & \\
\hline 21 & Pertimbangan keselamatan kerja & 0.6 & 4 \\
\hline 22 & Pertimbangan keamanan lapangan & 0.6 & 5 \\
\hline 23 & Tambahan fasilitas keamanan & 0.6 & 5 \\
\hline D. & FAKTOR ALAM & & \\
\hline 24 & Tanah longsor & 0.5 & 34 \\
\hline 25 & Banjir & 0.5 & 29 \\
\hline 26 & Penurunan tanah & 0.5 & 20 \\
\hline 27 & Cuaca yang tidak umum & 0.5 & 17 \\
\hline
\end{tabular}


Tabel 1. Hasil perhitungan Relative Importance Index secara Keseluruhan (lanjutan)

\begin{tabular}{|c|c|c|c|}
\hline$\bullet$ & KEBUTUHAN ADMINISTRASI & & \\
\hline A. & PERUBAHAN PERATURAN KERJA & & \\
\hline 1 & Perubahan dari peraturan perencanaan kota & - & - \\
\hline 2 & Perubahan berdasarkan perlindungan lingkungan & - & - \\
\hline B. & PERUBAHAN DARI PIHAK BERWENANG & & \\
\hline 3 & Perbedaan pandangan antara pejabat pemerintah & 0.4 & 49 \\
\hline 4 & Perubahan penempatan awal sarana dan prasarana & 0.5 & 38 \\
\hline 5 & Perubahan pasar & 0.4 & 44 \\
\hline 6 & Dominasi wewenang atasan/ pimpinan & 0.4 & 42 \\
\hline C. & COMMISSIONING & & \\
\hline 7 & Kebutuhan tambahan untuk perawatan/pemeliharaan & 0.5 & 21 \\
\hline 8 & Menambah kebutuhan untuk penggunaan proyek terkait & 0.5 & 17 \\
\hline 9 & $\begin{array}{l}\text { Kebutuhan tambahan untuk pertimbangan keselamatan } \\
\text { mendatang }\end{array}$ & 0.6 & 13 \\
\hline D. & PERMOHONAN LINGKUNGAN SEKITAR & & \\
\hline 10 & Penambahan fasilitas untuk penduduk & 0.6 & 7 \\
\hline 11 & $\begin{array}{l}\text { Mengurangi/ menunda bagian konstruksi sehubungan masalah } \\
\text { lingkungan }\end{array}$ & 0.5 & 23 \\
\hline 12 & $\begin{array}{l}\text { Permintaan pejabat/ pemerintah setempat CSR (Corporate } \\
\text { Social Responsibility) }\end{array}$ & 0.5 & 30 \\
\hline E. & PERUBAHAN LAIN & & \\
\hline 13 & Koordinasi yang terlambat disampaikan & 0.5 & 15 \\
\hline 14 & Keperluan dari institusi lain & 0.5 & 27 \\
\hline 15 & Konflik kontrak dan perselisihan & 0.5 & 34 \\
\hline$\bullet$ & PIHAK YANG TERLIBAT & & \\
\hline A. & PEMILIK & & \\
\hline 1 & Kurang control & 0.5 & 34 \\
\hline 2 & Ketidakmampuan pemilik & 0.4 & 46 \\
\hline 3 & Keterlambatan pemilik & 0.5 & 30 \\
\hline 4 & Hal-hal yang belum ditentukan pemilik & 0.5 & 25 \\
\hline 5 & Penundaan pekerjaan karena permintaan pemilik & 0.5 & 21 \\
\hline
\end{tabular}


Tabel 1. Hasil perhitungan Relative Importance Index secara Keseluruhan (lanjutan)

\section{B. KONTRAKTOR}

\begin{tabular}{rlrr}
\hline 6 & Kekurangan tim kerja & 0.5 & 39 \\
\hline 7 & Kurang memadai alat & 0.4 & 46 \\
\hline 8 & Kegagalan kemampuan kontraktor & 0.4 & 52 \\
\hline 9 & Perselisihan tenaga kerja & 0.4 & 43 \\
\hline 10 & Keterlambatan kontraktor & 0.4 & 44 \\
\hline 11 & Rendahnya keahlian pekerja & 0.4 & 51 \\
\hline 12 & Penundaan pekerjaan karena keterlambatan kontraktor & 0.4 & 46 \\
\hline C. & PIHAK LAIN & & \\
\hline 13 & Ketidakmampuan pihak ketiga & 0.4 & 41 \\
\hline 14 & Campur tangan pihak ketiga & 0.5 & 37 \\
\hline
\end{tabular}

\section{KESIMPULAN DAN SARAN}

Berdasarkan analisis dan pembahasan yang telah dilakukan, maka dapat disimpulkan:

1. Faktor penyebab terbesar Change berdasarkan yang disusun berdasarkan peringkat adalah

1. Ketidakcocokan antara gambar design dan keadaan lapangan

2. Perubahan gambar perencanaan

3. Penambahan ruang lingkup kerja

2. Faktor penyebab terbesar Change Order terbesar setiap kategori pertanyaan adalah

a. Perencanaan dan Design

- Ketidakcocokan antara gambar design dan keadaan lapangan

- Perubahan gambar perencanaan

b. Kondisi Bawah Tanah

- Peningkatan dan penyelidikan bawah tanah

c. Pertimbangan Keselamatan

d. Faktor Alam

- Pertimbangan keselamatan kerja

- Cuaca yang tidak umum

e. Perubahan Dari Pihak Berwenang

- Perubahan penempatan awal sarana dan prasarana

f. Commissioning

- Kebutuhan tambahan untuk pertimbangan keselamatan mendatang

g. Permohonan Lingkungan Sekitar

- Penambahan fasilitas untuk penduduk

h. Perubahan lain

i. Pemilik

- Koordinasi yang terlambat disampaikan

j. Kontraktor

- Penundaan pekerjaan karena permintaan pemilik

k. Pihak Lain

- Kekurangan tim kerja

- Campur tangan pihak ketiga

\section{DAFTAR PUSTAKA}

Barrie, Donal S., \& Paulson, Boyd C. Professional Construction Management ( $3^{\text {rd }}$ ed.)., Civil Engineering Series. Singapore: MC Graw-Hill Inc, 1992.

Fisk, Edward R. Construction project Administration ( $5^{\text {th }}$ ed.). New Jersey: Prentice Hall, 1997. 
Gilbreath, Robert D. Managing Construction Contract Operational Control for Commersial Risk (2 ${ }^{\text {nd }}$ ed). John Wiley \& Sos,Inc, 1992.

Sulistio, Hendrik., \& Mega Waty. "Analysis and evaluation change order in flexible pavement". Media Komunikasi Teknik Sipil, 2008. 